BIOMEDICA

Vol. 9, Nos. 3 y $4-1989$

COMUNICACION DE CASOS

\title{
HIPERPLASIA EPITELIAL FOCAL DE LA BOCA EN COLOMBIA (ENFERMEDAD DE HECK)
}

\author{
GERZAIN RODRIGUEZ TORO*
}

\begin{abstract}
El estudio de biopsias orales remitidas al INS por médicos y odontólogos en Servicio Social Obligatorio en la Amazonía y la Orinoquía y de especímenes de consulta enviados desde el Chocó, Boyacá y el Quindío, demuestra la amplia difusión de la hiperplasia epitelial focal en Colombia. La entidad tiene predominio notorio en las comunidades indígenas. Las lesiones son pápulas numerosas en las mucosas del labio inferior, los carrillos y los bordes de la lengua, que afectan a menores de 16 años y a algunos adultos. Tienden a evolucionar durante años y son asintomáticas. La histopatología revela hiperplasia epitelial global, anastomosis de las crestas, células mitosoides, vacuolización alta y frecuente binucleación de queratinocitos en la mitad superior del epitelio. Con la técnica de PAP y con M.E. se demuestra antígeno de Papilomavirus en las células malpighianas altas y en las células córneas paraqueratósicas. La HEP debe ser bien reconocida por médicos y odontólogos, principalmente por aquellos que prestan su servicio a comunidades indígenas.
\end{abstract}

\section{INTRODUCCION}

La hiperplasia epitelial focal de la boca (HEF) es una afección papulosa y nodular que afecta la mucosa labial, los carrillos, la lengua, el paladar y la encía de los niños y jóvenes, principalmente indígenas y esquimales $(1,2)$. Con microscopía electrónica se demostró un Papilomavirus en el epitelio hiperplásico $(3,6)$, que con métodos inmunológicos y de hibridización molecualr se catalogó como tipo 13 (HPV-13) y 32 (HPV-32), este último entre esquimales y daneses $(7,8)$.

Luego de la caracterización inicial de la afección en 15 indios Navajos de Nuevo México, en dos indígenas del Sur de EE.UU., en un niño esquimal y en un indígena Chavante de Matto Grosso, Brasil (1), se publicaron múltiples informes sobre la presencia de la entidad en varias comunidades indígenas latinoamericanas $(9,12)$, en algunas de las cuales es tan conocida como para asignársele por los nativos el nombre de "mollejas" (12). La prevalencia entre indígenas americanos se estimó entre 3 y $30 \%(9,13)$, cifra que puede ser mayor entre los esquimales $(2,5)$. Un porcentaje intermedio se calcula para los "colorados" (Cape Coloureds) de Africa del Sur (14).

Existen informes esporádicos de la HEF de la boca en otras regiones y razas $(14,21)$, siendo rara su presentación en caucásicos $(17,20,21)$. Está bien definida su ocurrencia intrafamiliar $(13,22,23)$.

* Jefe del Grupo de Patología, Instituto Nacional de Salud. Bogotá, Apartado Aéreo 80334.

Profesor Titılar de Cátedra de los Departamentos de Morfología y Patología de la Facultad de Medicina de la Universidad Nacional. Bogotá - Colombia. 


\section{MATERIAL Y METODOS}

\section{A. Historias clínicas y biopsias:}

1. Cuarenta y dos biopsias de la entidad con datos generales de los pacientes se han recibido en el Grupo de Patología del INS durante los últimos 6 años, procedentes principalmente de comunidades indígeneas y de colonos de Guainía, Vichada y Vaupés, sitios desde donde los especímenes son remitidos en formol tamponado, por médicos y odontólogos que prestan su Servicio Social Obligatorio.

2. Diecisiete especímenes de consulta provenientes de Bogotá, Tunja, Sogamoso, Quibdó y Armenia.

\section{B. Inmunoperoxidasa:}

En 7 casos se han hecho observaciones preliminares con técnica inmunoenzimática para la demostración de antígeno de Papilomavirus, utilizando tejido fijado en formol y reactivos DAKO, con técnica de PAP indirecta (24).

\section{Microscopía electrónica:}

En cinco casos ha sido posible disponer de especímenes bien preservados, fijados en formol tamponado o en glutaraldehído al 3\% en solución tampón de fosfatos, pH. 7.3, que luego de postfijación eli OsO4 al $1 \%$ se han incluido en resinas epóxicas, cortado y examinado al microscopio electrónico.

\section{RESULTADOS}

\section{A. Clínica y epidemiología:}

La enfermedad afecta principalmente a niños entre los 3 y 16 años de edad (70\%) (Figs. 1-5), pero no es rara en los adultos (30\%). Predomina en las comunidades indígenas de la Amazonia y la Orinoquia pero se observa también entre colonos y sus hijos, negros, mestizos y blancos. Las lesiones son múltiples pápulas y nódulos de superficie lisa, plana y amplia base de implantación, rosados o del mismo color de la mucosa adyacente, con tamaños entre 2 y $7 \mathrm{~mm}$. Tienden a desaparecer cuando se distiende la mucosa. Afectan siempre el labio inferior y luego los carrillos, los bordes linguales y el labio superior (Figs. 1-5). Rara vez comprometen el paladar o las encías y no existen descripciones de su presencia en la orofaringe o en la úvula. Son asintomáticas pero cuando son muy profusas en niños menores, pueden interferir con su alimentación o sufrir infección secundaria. Se presentan casos intrafamiliares en 2 ó 3 hermanos. Ocasionalmente se han observado verrugas vulgares concomitantes en los dedos de los mismos pacientes. No se han registrado observaciones convincentes de regresión espontánea de la entidad, hecho atribuido a la dificultad de seguimiento de estas poblaciones que tienden a ser nómadas. La evolución es crónica, sin aparición de lesiones nuevas luego de la fase incial de instauración de la enfermedad. En una indígena de 28 años de edad y en un colono de 50, su HEF ha estado presente durante 20 años.

Observaciones de evoluación entre 5 y 15 años son frecuntes, pero la mayoría han estado presentes por menos de un año. Los oficiales locales de salud no conocían la entidad pero con la asesoría prestada a través de las biopsias enviadas se ha generalizado la indentificación de HEF que sólo se somete a tratamiento de extirpación quirúrgica o se deja a su evolución natural. No se ha observado transformación maligna y no se han hecho estudios sobre factores de riesgo para adquirirla, sobre prevalencia de las lesiones en las comundiades indígenas ni sobre recurrencia post-tratamiento.

\section{B. Histopatología:}

Muestra un cuadro típico que confiere autonemía a la enfermedad y que la diferencia de otras lesiones mucosas producidas por los Papilomavirus. (Figs. 613). Se caracteriza por:

- Hiperplasia epitelial global con anastomosis transversales entre las columnas epiteliales. Se observa en todas las biopsias.

- La hiperplasia horizontal de la punta de las crestas interpapilares origina un aspecto morfológico que se ha comparado con un hacha de la edad de bronce (25), (Fig. 8). Lo observamos en el $10 \%$ de las biopsias.

- Aumento moderado del número de mitosis en los estratos basales. 


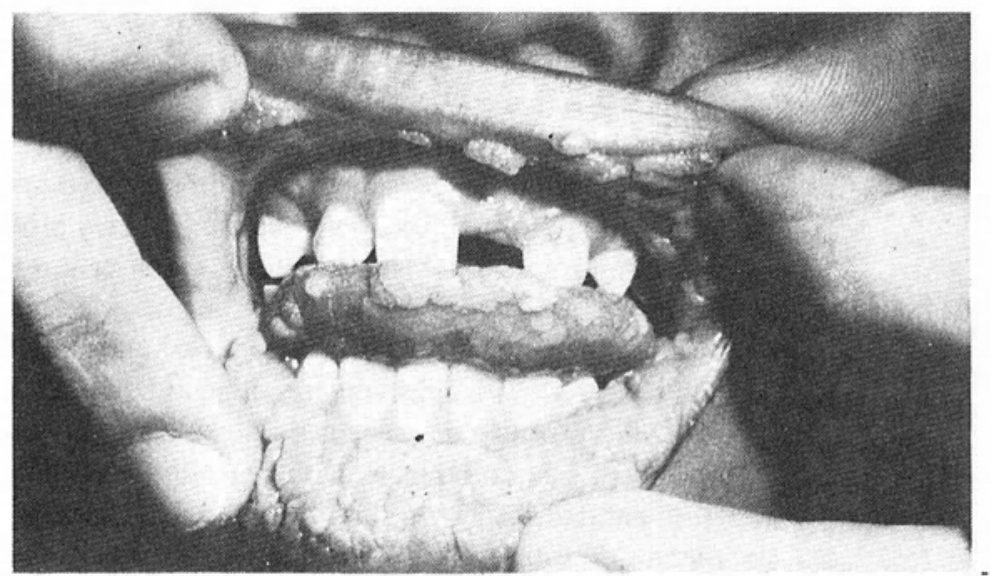

Fig. 1. Lesiones papulosas profusas de los labios, la lengua y los carrillos en una niña indígena de Guainía, de 6 años de edad.

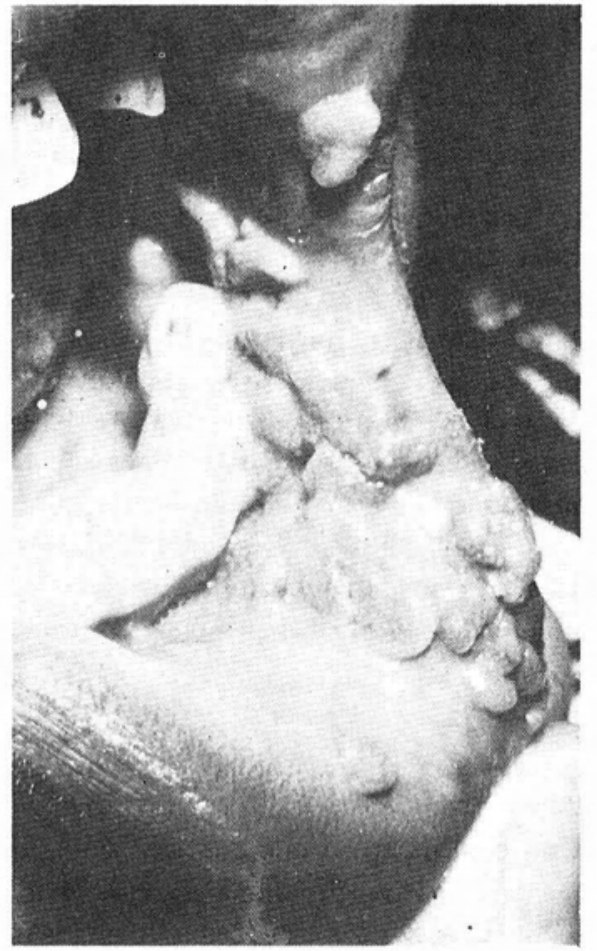

Fig. 2. Abundantes lesiones papulosas sesiles, en el labio inferior y en el carrillo en una niña de 14 años de edad. Una hermana presentaba lesiones semejantes.

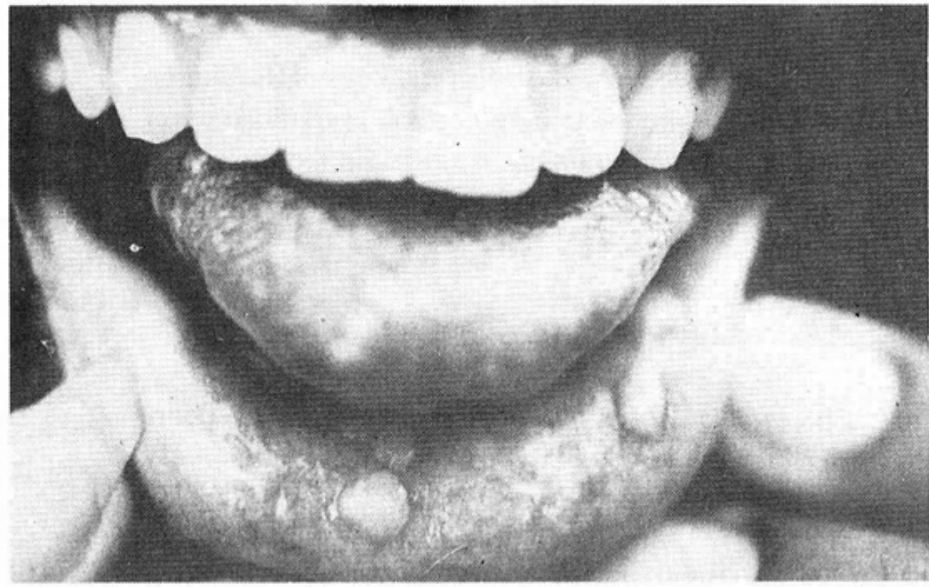

$\Delta$ Fig. 3. Pápulas en el labio inferior y la lengua en un joven de raza negra del Chocó.
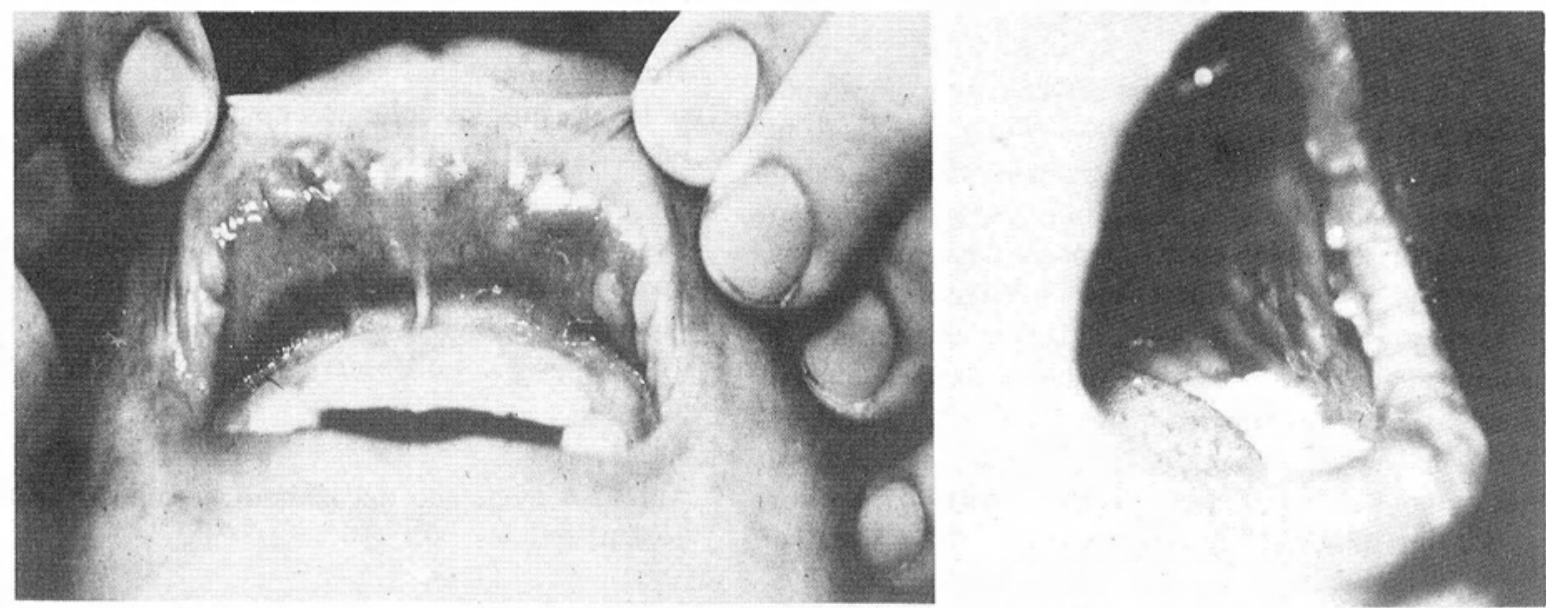

$\Delta$ Fig. 4 y 5. Pápulas aplanadas en el labio superior, en los carrillos y en el labio inferior en un indígena de 14 años del Guainía. Las lesiones del labio superior son excepcionales. 


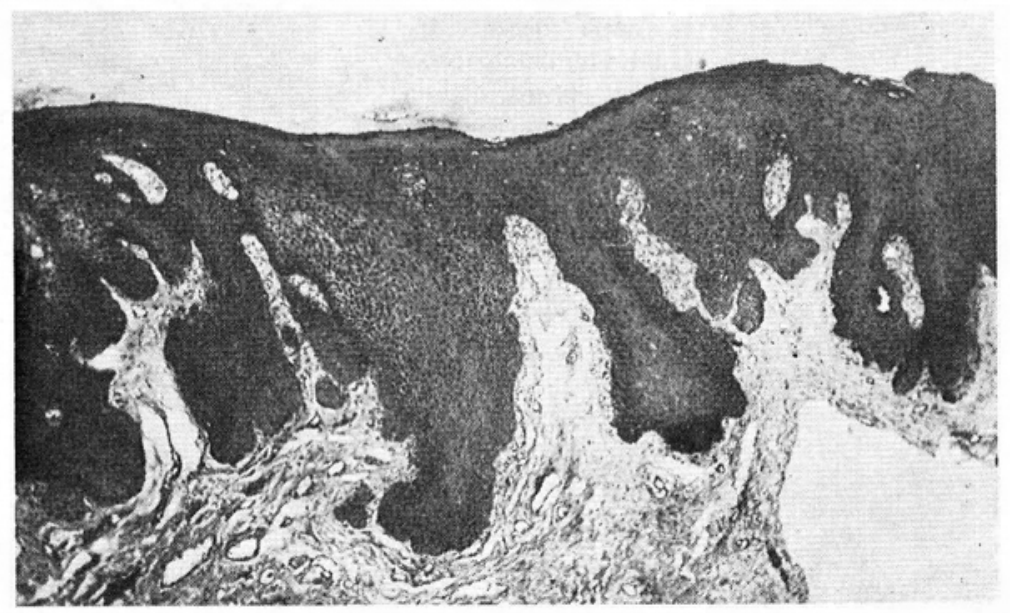

Fig. 6. Hiperplasia epitelial irregular severa con anastomosis de las crestas interpapilares. HE.4X. Biopsia del paciente de la figura 3.

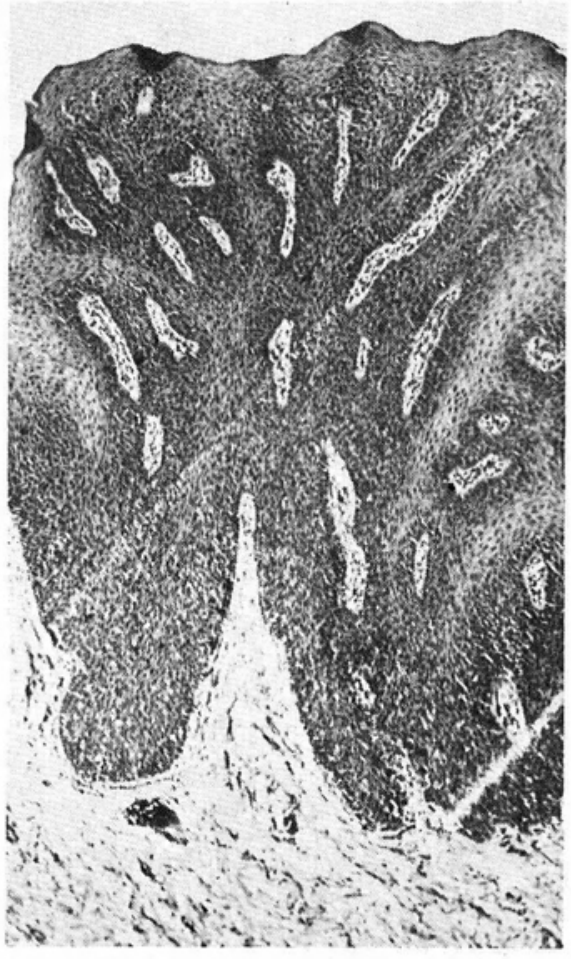

Fig. 7. Hiperplasia epitelial nodular con anastomosis de las crestas interpilares y papilomatosis. Biopsia de la paciente de la figura 1. HE. 63X.

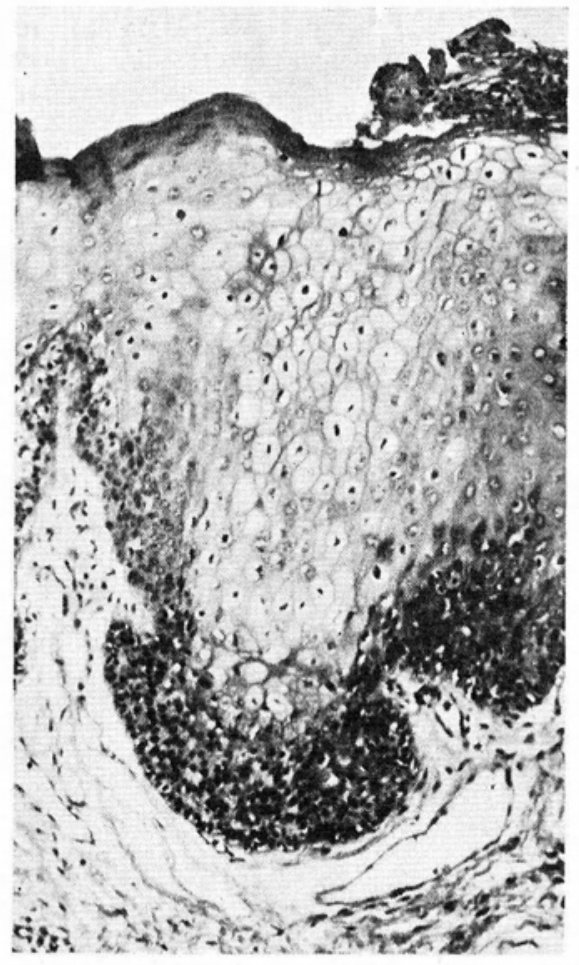

Fig. 8. Hiperplasia de la punta de las crestas en forma de "hacha de la edad de bronce". Se aprecia también vacuolización citoplasmática. HE.100X. 


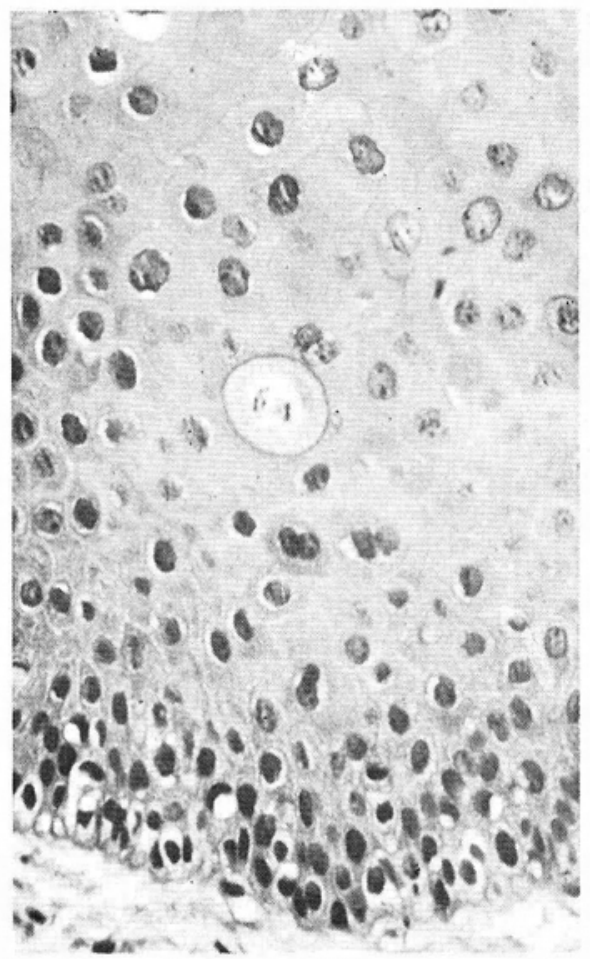

Fig. 9. Hiperplasia de la capa basal, frecuente binucleación, y en el centro, célula grande, clara con fragmentación nuclear (célula mitosoide). Imagen del tercio inferior del epitelio. HE. $400 X$.

Fig. 10. Vacuolización citoplasmática, núcleos irregulares con binucleación y célula mistoide. Tercio superior del epitelio. HE.400X
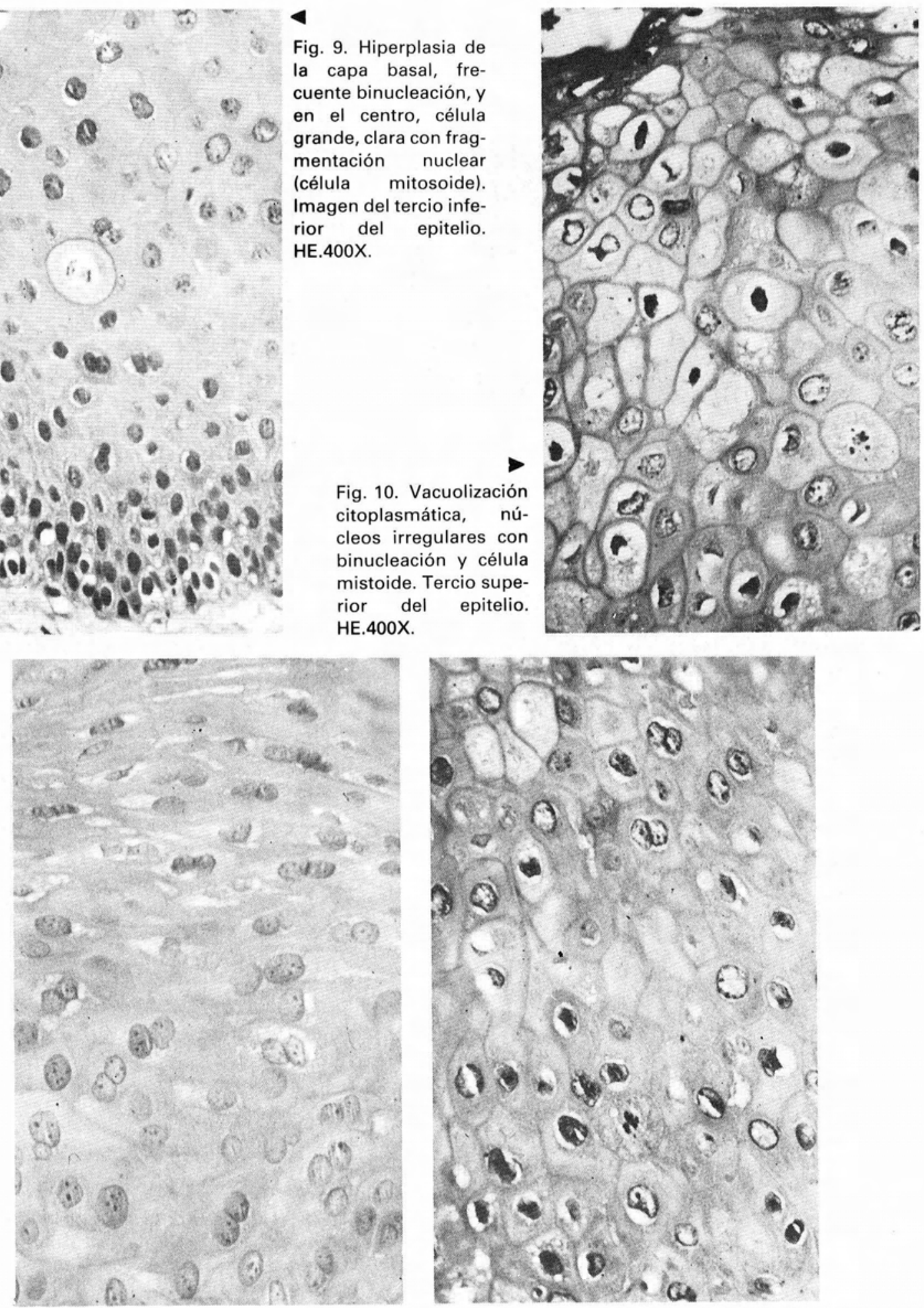

Fig. 11 y 12. Binucleación celular muy aparente en el tercio superior del epitelio. En la fig. 12 se ven además células vacuoladas y una célula mitosoide. HE.400X. 


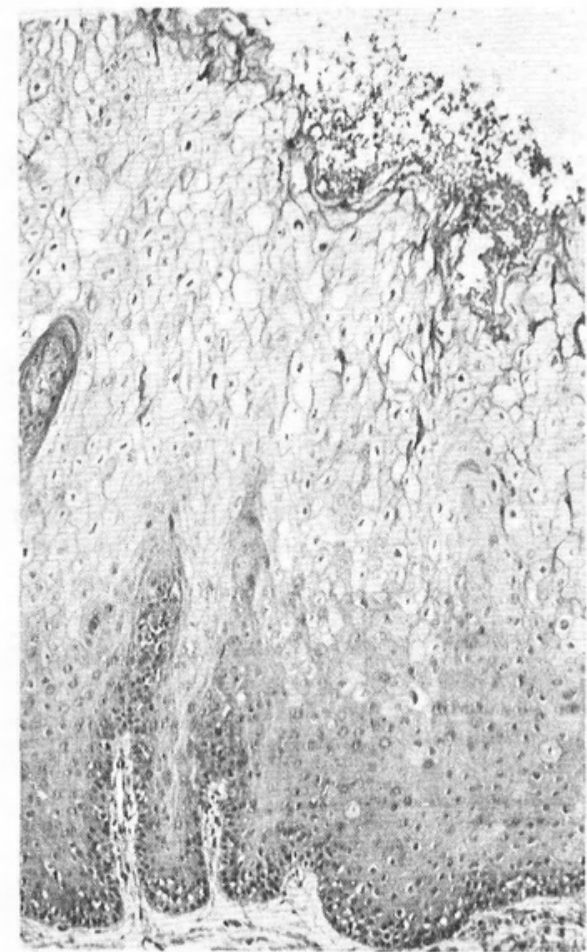

Fig. 13. Fotografía panorámica de todo el grosor del epitelio. La vacuolización citoplasmática (Coilocitosis) es el cambio más prominente de los dos tercios superiores de la epidermis. Se ven células mitosoides en el tercio inferior de ésta. Biopsia de la lengua de la paciente de la figura 1 . HE $100 x$.

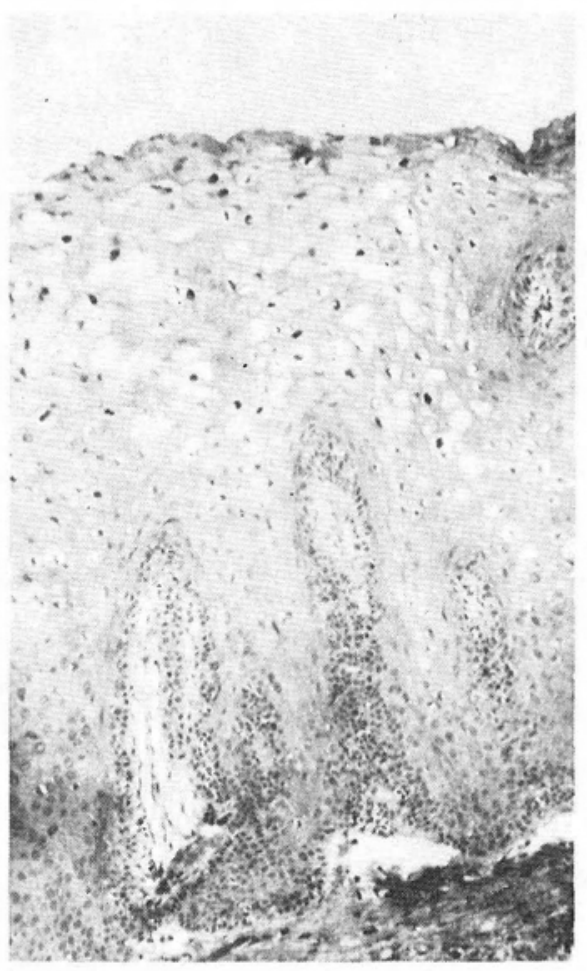

Fig. 14. Vista panorámica de un área equivalente a la ilustrada en la figura 13. Técnica de PAP para demostrar Papilomavirus. La positividad de la reacción se revela como núcleos oscuros, densos en la mitad superior del epitelio. PAP 100X.
- Binucleación celular frecuente, en la mitad superior del epitelio, mayor que en cualquier otro tipo de verruga. Se observa en todas las biopsias.

- Presencia de "células mitosoides" en el estrato malpighiano. Son células grandes, claras. redondeadas y abombadas, con varios cuerpos cromatínicos intranucleares, que sugieren a primera vista una mitosis; la observación detallada y el análisis untraestructural indican que son células disqueratósicas. Son también un rasgo histopatológico único de esta entidad, presente en todas las biopsias. (Figs. 9-12).

- Hiperqueratosis paraqueratósica y compacta, mayor que aquella propia del epitelio bucal.
- Focos de células malpighianas en el tercio medio y superior del epitelio con vacuolización citoplasmática notoria, algunas de las cuales contienen también pequeños y dispersos gránulos de queratohialina. Pueden ser binucleadas y no alojan cuerpos de inclusión intranucleares.

- En el tercio inferior del epitelio se demuestran numerosas célulosas de Langerhans y en la capa basal del mismo se ven melanocitos. (Fig. 23).

En el corion no hay infiltrados inflamatorios. Las papilas son profundas, poco ramificadas y contienen capilares dilatados. 


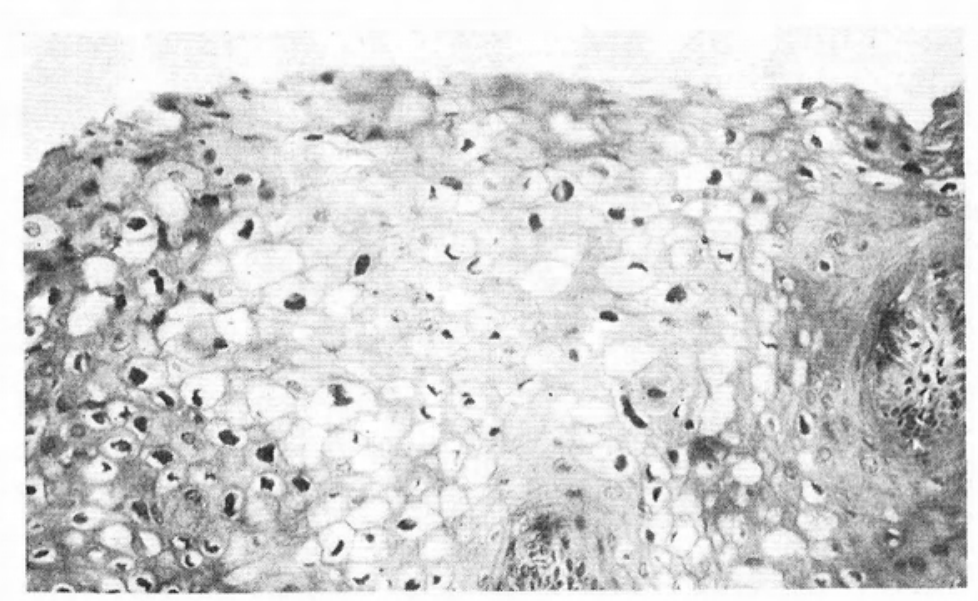

Figs. 15 y 16 . Mayores aumentos de la lesión anterior que revelan la abundancia de antígeno de Papilomavirus en los núcleos de la mayoría de los queratinocitos presentes. Nótese que algunas células binucleadas dan reacción negativa. No obstante, el microscopio electrónico demostró virus en ellas. (Véase fig.17). Fig. 15 PAP $160 X$ Fig. 16 PAP 400X.

\section{Inmunoperoxidasa:}

Se demostraron antígenos de Papilomavirus en 5 de los 7 casos estudiados, en los núcleos de células del tercio externo del epitelio (Figs. 14-16), incluyendo las binucleadas y paráqueratósicas. Las células con reacción positiva no son muy numerosas y su distribución es a parches dentro de la biopsia. La positividad es mayor en las biopsias de la lengua.

\section{Microscopía electrónica:}

Demuestra viriones intranucleares en algunas células del tercio superior del epitelio, coincidiendo con las áreas positivas con la técnica inmuno enzimática. Los virus, aislados o formando pequeños cristales (Figs. 17-21), no rechazan periféricamente la croma- tina nuclear ni constituyen conglomerados, por lo cual no originan inclusiones visibles al microscopio de luz. Las células binucleadas pueden contener viriones aislados (Fig. 17).

La vacuolización citoplasmática se debe a escasa cantidad de tonofilamentos y a extracción del contenido citoplasmático durante el proceso de la biopsia.

Las células mitosoides tienen acúmulos de heterocromatina, nucleolos condensados y citoplasma filamentoso compacto, por lo cual las interpreto como células disqueratósicas; a veces se ven células de Langerhans en su vecindad. Estas, al igual que los melanocitos, se demuestran con frecuencia en la base del epitelio. (Fig. 22). 


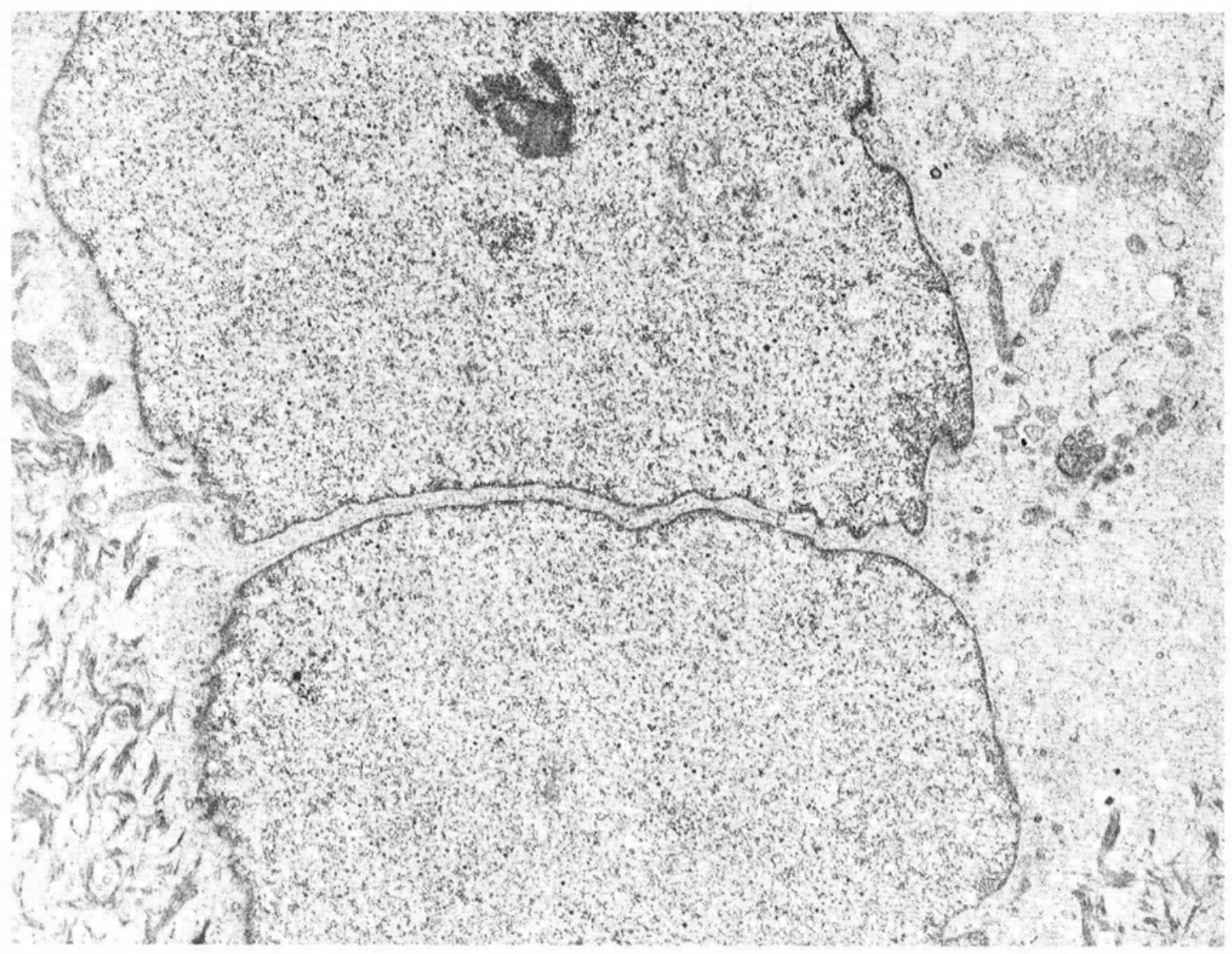

Fig. 17. Célula malpighiniana binucleada con puntos densos intranucleares diminutos y escasos (45 $\mathrm{nm}$ ) que corresponden a Papilomavirus. 12.000X.

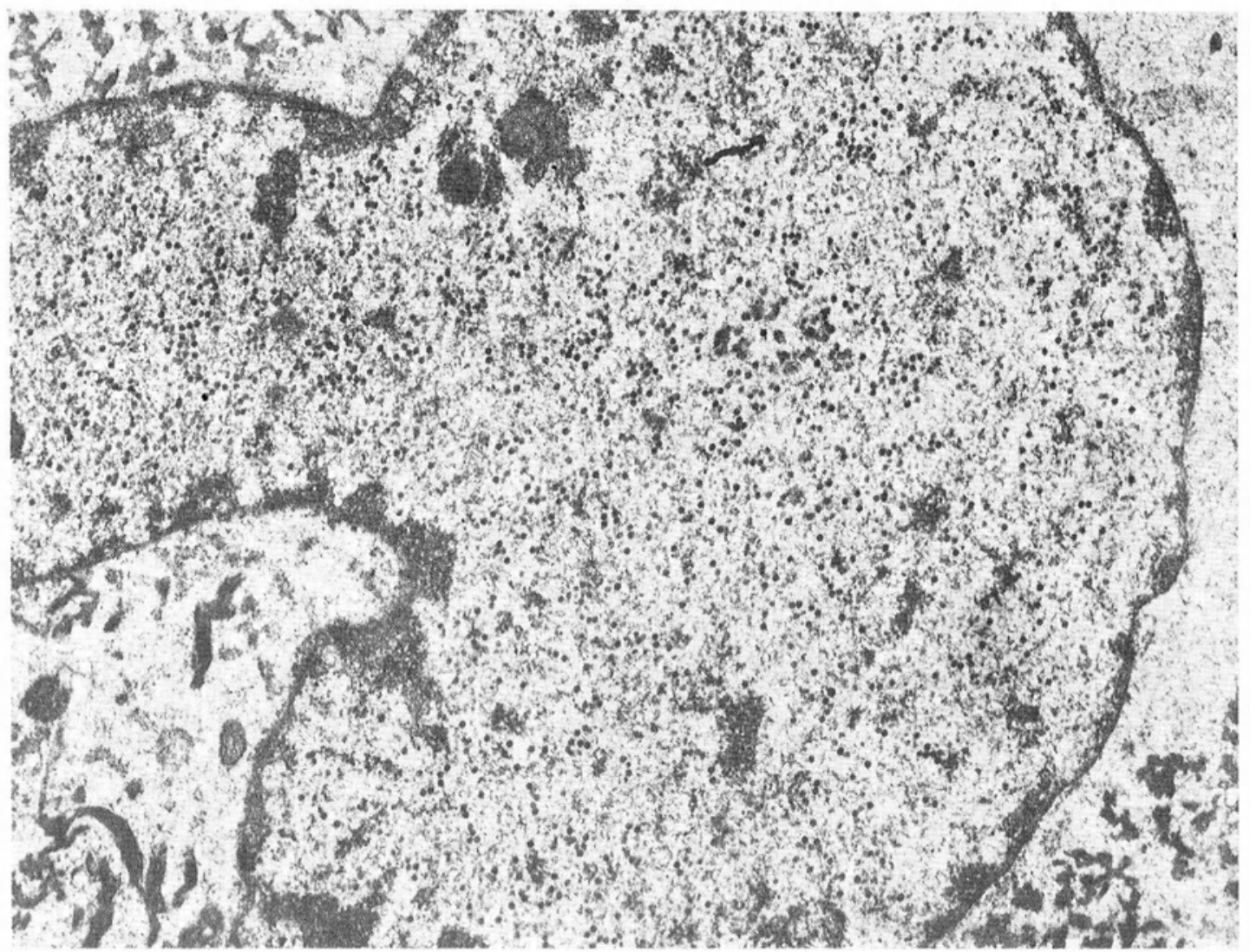

Fig. 18. Núcleo irregular con cromatina discretamente marginada sobre la membrana nuclear y con abundantes partículas virales dispersas que no tratan de formar cristales. 16.000X. 

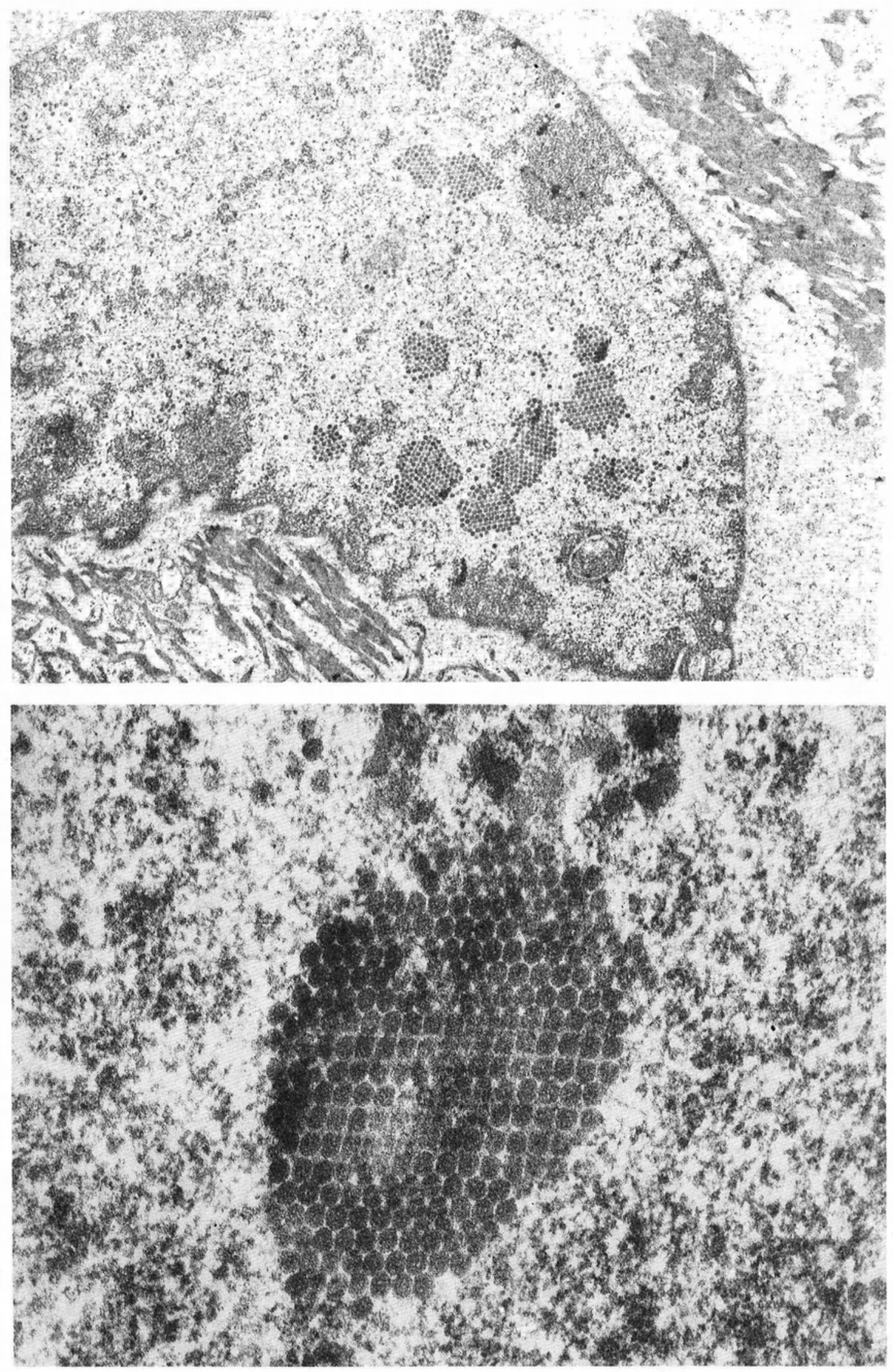

Fig. 19 y 20. Pequeños grupos de Papilomavirus formando cristales no confluentes en esta célula alta del epitelio. La discreta magnitud de los acúmulos virales no permite su detección como inclusiones al microscopio de luz. A la izquierda de ambas electromicografias se ven partículas virales sueltas. Fig. 19, 21.000X Fig. 20, 87.000X. 


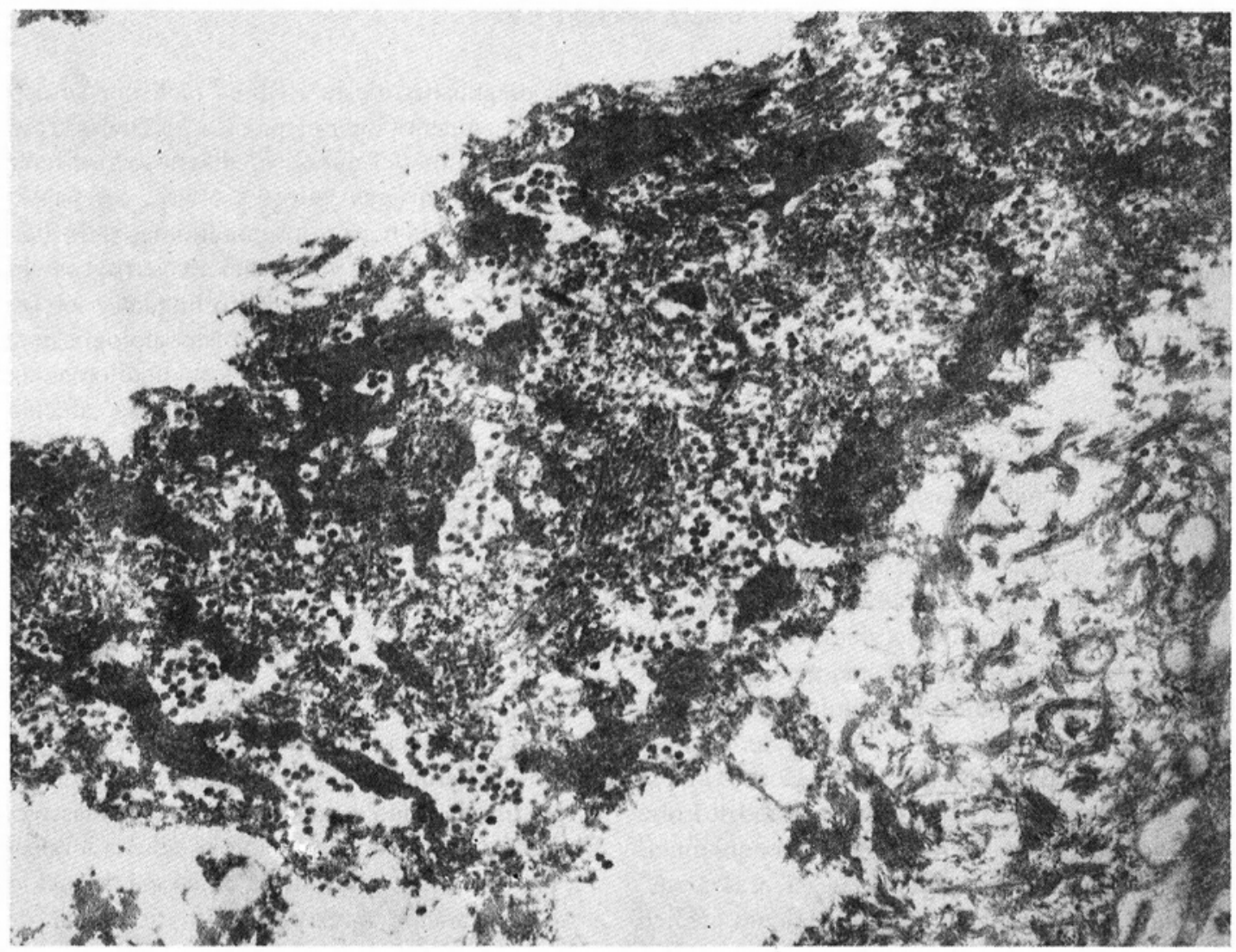

Fig. 21. Ultima célula de la capa epitelial. El núcleo se ha disuelto y los virus, libres, ocupan el citoplasma entre los filamentos y restos nucleares densos. La auto o heteropropagación viral se deduce de este aspecto morfológico. 21.000X.

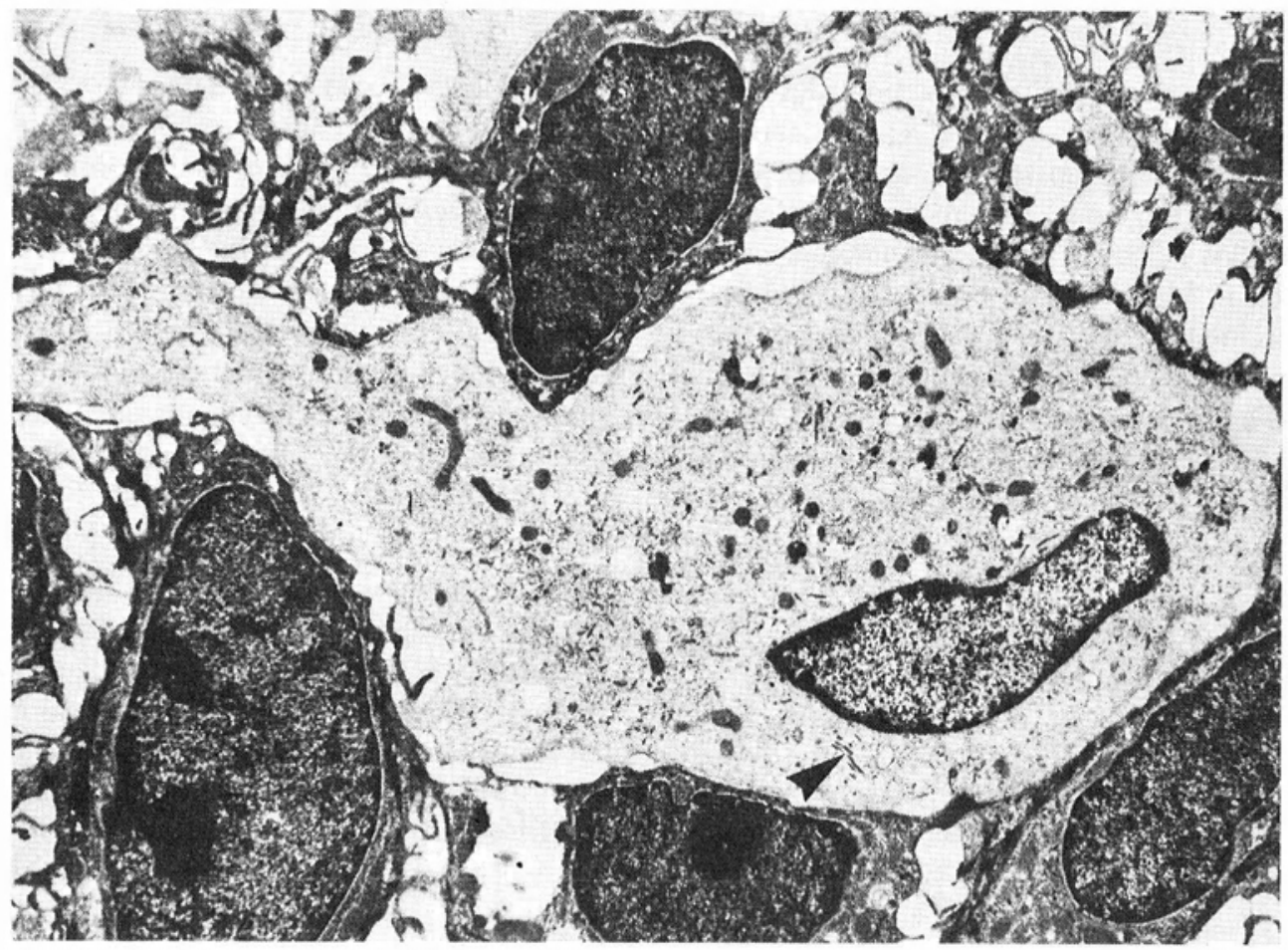

Fig. 22. Prominente célula clara de Langerhans en el centro de la figura, rodeada por queratinocitos. La flecha apunta hacia los gránulos de Birbeck, que son muy numerosos por todo el citoplasma. 6.000X. 


\section{DISCUSION}

Los datos aquí presentados demuestran que la $\mathrm{HEF}$ tiene amplia distribución en Colombia. Es una entidad común entre los indígenas de la Amazonia y de la Orinoquia y tiende a presentarse en comunidades rurales (Chocó, Boyacá), con muy pocos casos provenientes de las ciudades.

La recopilación de esta abundante casuística se debe al desplazamiento de médicos y odontólogos a estas zonas selváticas, como consecuencia de la escasez de cargos para realizar el Servicio Social Obligatorio en la vecindad de los grandes centros urbanos, a la gran competencia aparecida por la graduación anual de más de 1.500 médicos y a que los servicios de salud de la Amazonia y la Orinoquia pagan mejores salarios. A través de estos profesionales, que remiten las biopsias de sus pacientes al INS, no sólo hemos demostrado la gran frecuencia de la enfermedad de Heck, sino de otras entidades esotéricas como la enfermedad de Lobo y el pénfigo de la selva. Merced a esta labor conjunta, estas nosologías antes desconocidas en esas áreas, forman ahora parte esencial del conocimiento médico de los oficiales locales de la salud y deben constituir información básica oblicatoria para los profesionales de la salud pública que se desplacen a trabajar en estas áreas.

La HEF había sido descrita en comunidades indígenas latinoamericanas en Colombia, Guatemala y Venezuela (26-29), pero no se cayó en la cuenta del aspecto epidemiológico sui-generis de la entidad ni se difundieron los hallazgos en revistas internacionales. A pesar de la toma de biopsias (26) no se hizo la caracterización histopatológica de la enfermedad ni se sugirió su etiología, hechos todos que fueron bien precisados en la publicación que dió nombre a la entidad (1). En la publicación de un estudio médico-antropológico en indígenas de Antioquia se lee y se ilustra (26):

"DE MUCHO INTERES CONSIDERAMOS EL HALLAZGO DE UNA ESPECIE DE VERRUGA INTRAORAL CON ASPECTO DE COLIFLOR, ENTRE LOS KATIOS DE EL PIÑON; YA LA HABIAMOS VISTO EN LOS CARAMANTAS KATIOS DE EL JARDIN. ESTA VERRUGA SE LOCALIZA EN LOS BORDES $Y$ EL DORSO DE LA LENGUA Y EN LA PARTE INFERIOR DE LAS MEJILLAS Y DE LOS LABIOS. (Fig. 16)".
El diagnóstico de la HEF es fácil por su aspecto clínico y epidemiológico típicos, a los cuales la biopsia añade criterios definidos. El diagnóstico diferencial incluye las verrugas vulgares orales, los papilomas escamosos de la boca y los condilomas (30). Las dos primeras son lesiones virales únicas o en poco número, que afectan las encías, el dorso lingual y los labios, con superficie papilomatosa e histopatología sin células mitosoides ni binucleación. Los condilomas acuminados de la boca pueden ser múltiples, afectan los labios, la lengua, la encía, el paladar, la úvula y son pequeños, pedunculados, papilomatosos o con aspecto de coliflor (30). En la mayoría de los casos se acompañan de condiloma anogenital concomitante (30). La histopatología es rica en células vacuoladas y no muestra células mitosoides. Pueden mostrar displasia importante que no se ve en la HEF.

El nevus blanco esponjoso muestra pápulas aplanadas de los labios que histológicamente corresponden a hiperplasia epitelial de células vacuoladas repletas de glicógeno, sin binucleación ni células mitosoides. La papilomatosis oral florida es un carcinoma verrucoso con carácter agresivo e infiltrativo local, que se presenta en ancianos con enfermedad básica debilitante o con antecedentes de irritación oral cancerígena como "fumar hacia adentro" o ingestión de arsénico $(30,31)$.

El tratamiento de la HEF como el de todas las lesiones producidas por Papilomavirus es múltiple, poco específico y sujeto a controversia porque puede presentarse curación espontánea por activación de la respuesta inmune celular del huésped, una vez que las células de Langerhans se "enteran" de la presencia del antígeno extraño y lo presentan a los linfocitos, localmente o en el ganglio linfático. La abundancia de estas células en los especímenes que estudiamos al microscopio electrónico es un índice indirecto de la puesta en marcha de este mecanismo.

Algunos aconsejan no hacer tratamiento y esperar la involución espontánea que debe ocurrir en 1-3 años (30). En varios de nuestros pacientes la evolución ha sido muy crónica, de décadas, por lo cual la extirpación local, la crioterapia o la inmunoterapia deberían ser ensayadas. Las lesiones profusas en niños menores también deben tratarse por cuanto las erosiones y la infección secundaria pueden interferir con su alimen- 
tación. Como es la regla con los Papilomavirus las recurrencias son frecuentes (30).

Los Papilomavirus que producen lesiones en el humano pasan ya de 60 tipos (30). Los HPV-13 y 32 son hasta ahora los responsables de la HEF (7-8). Como es usual con estos agentes, es de esperarse colonización múltiple de las lesiones, la tipificación de nuevos virus en las mismas y la eventual aparición de huéspedes anérgicos, sin respuesta inmune ante el virus que puede así producir lesiones profusas y persistentes.

La HEF es una entidad autónoma clínica e histopatológicamente en la cual los tipos 13 y 32 de Papilomavirus producen hiperplasia epitelial de evolución crónica, principalmente en comunidades indígenas que posiblemente tengan susceptibilidad genética para el agente causal.

\section{SUMMARY}

The widespread distribution of focal epithelial hyperplasia $(\mathrm{FEH})$ in Colombia, specially among indian communities of the Amazonia and Orinoquia regions is described. Our observation has been supported by the study of clinical data and biopsy specimens sent to us by physicians and dentists during their compulsory rural year. Lesions consist of numerous papules and nodules on the mucous surface of the lower lip, cheeks and tongue borders, affecting mainly children under 16 years of age and some adults. They present a chronic evolution lasting several years and are, generally, asymptomatic. Histopathology shows global epithelial hyperplasia with anastomoses of the rete pegs, "mitosoid" cells, vacualization and frequently, keratinocyte binucleation in the upper half the epithelium. Using Pap Techniques Papilomavirus antigen is demostrated in nuclei of the upper external portion of the epithelium. Electron microscopy showed isolated virions and small intranuclear cristals of Papilomavirus in higher malpighian cells and in parakeratotic cells in the horny layer. Physicians and dentists should be well aware of the existence of FEH, specially those working with indian communities.

\section{AGRADECIMIENTOS}

A los doctores Felipe Jaramillo, Mariano López, Alvaro Peynado y Mitchel Faisal por las fotografías clínicas Nos. 1, 2, 3 y 4-5, respectivamente.
A las bacteriólogas Patricia J. de Naranjo y Leonor Cipagauta Galvis por su cooperación en la realización de las técnicas de PAP y de microscopía electrónica.

Al señor Enrique Rivera por el trabajo fotográfico y a la señora Matilde de Mojica por mecanografiar el manuscrito.

\section{BIBLIOGRAFIA}

1. Archard H, Heck J, Stanley H. Focal epithelial hyperplasia: An unusual oral mucosal lesion found in indian children. Oral Surg, Oral Med, Oral Path. 1965; 20: 201-212.

2. Praetorius-Clausen $F$, Mogeltoft $M$, Roed-Petersen $B$, et al. Focal epithelial hyperplasia of the oral mucosa in a southwest greenlandic population. Scan J Dental R. 1970; 78: 287.

3. Praetorius-Clausen F, Wilis J. Papova virus like particles in focal epithelial hyperplasia. Scand J Dental Res. 1971; 79: 362.

4. Hankes CT, Fischman SL, Niño MG. Focal epithelial hyperplasia. A light and electronmicroscopic study of 1 case. Oral Surg, Oral Med, Oral Path. 1972; 33: 934-942.

5. Lutzmer M, Kuffer R, Blanche-Borden C et al. Different papilloma viruses as the causes of oral warts. Arch Dermatol. 1982; 118: 393-399.

6. Lutzmer MA. Virus disease of the skin and mucosa. in: Electron microscopy in human medicine. The skin, volume 11 (a). Edi Jan Vicents Johannesen and K Hashimoto. Mc graw-Hill 1985; pp 277.

7. Pfister $\mathrm{H}$, Hettich I, Rumme U, et al. Characterization of human papillomavirus type 13 from focal epithelial hyperplasia Heck lesions. J Virol 1983; 47: 363.

8. Beaudenon S, Praetorius F, Kempsdorf D, et al. A new type of human papillomavirus associated with oral focal epithelial hyperplasia. J Invest Dermatol 1987; 88: 130135.

9. Witkop C, Niswander J. Focal epithelial hyperplasia in central South American Indians and Ladinos. Oral Surg, Oral Med, Oral Path. 1965; 213-217.

10. Tan K, Medak H, Cohen L, et al. Focal epithelial hyperplasia in a mexican indian Arch Dermatol. 1969; 100 : 475-477.

11. Galindo D, Niño M. Focal epithelial hyperplasia. Report of four cases in mestizos from Cochabamba, Bolivia. Oral Surg, Oral Med, Oral Path. 1969; 27: 15-19. 
12. Firhman SL. Focal epithelial hyperplasia. Case reports from Paraguay and Perú. Oral Surg, Oral Med, Oral Path. 1969; 28: 389-393.

13. Gómez A, Calle C, Arcila G, et al. Focal epithelial hyperplasia in a half-breed family of colombians. JADA. 1969; 79: 663-667.

14. Van Wyk C. Focal epithelial hyperplasia of the mouth recently discovered in South Africa. Br J Dermatol. 1977; 96: 381-388.

15. Perryman A, Uthman A. Focal epithelial hyperplasia. Report of 7 cases from Iraq. Oral Surg, Oral Med, Oral Path. 1971; 31: 221-225.

16. Buchner A, Ramon Y. Focal epithelial hyperplasia. Report of two cases from Israel and review of the literature. Arch Dermatol. 1973; 107: 97-98.

17. Starink T, Woerdeman J. Focal epithelial hyperplasia of the oral mucosa. Report of two cases from the Netherlands and review of the literature. $\mathrm{Br} \mathrm{J}$ Dermatol. 1977; 96: $375-380$.

18. Stiefler R, Solomon R, Shalita A. Heck,s diasease (Focal epithelial hyperplasia). J Am Acad Dermatol. 1979; 1: 499-502.

19. Rodríguez F, Soares $P$, Lopes C. Hyperplasia focal epithelial (Doenca de Heck) Med Cut ILA. 1985; 13: 13-16.

20. Moussavi S. Focal epithelial hyperplasia. Report of two cases and review of the literature. JADA. 1986; 113: 900-902.
21. Samsom J, Fior-Douno G, Avizara N. L'hyperplasie epitheliale focale: Premiers cas suisses et revue de la litterature. Dermatológica. 1985; 171: 308-315.

22. Shock RK. Familial focal epithelial hyperplasia. Report of case. Oral Surg, Oral Med, Oral Path. 1969; 28: 598-602.

23. Buchner A, Mass E. focal epithelial, hyperplasia in an Israeli family. Oral Surg, Oral Med, Oral Path. 1973; 36: 507-511.

24. Bourne JA. Handbook of immunoperoxidase staining methods. Dako Corporation, USA. 1983.

25. Praetorius-Clausen F. Histopathology of focal epithelial hyperplasia. Tandlaegebladet. 1969; 73: 1013.

26. Estrada L. Informe proliminar sobre algunos aspectos odontológicos de los indios Caramanta. Boletín inst. Antropol, U de Antioquia. Tomo 4. 1956; 1: 319-321.

27. Estrada L. Estudio médico y odontológico de los indios Katíos del Chocó. Temas odontológicos. 1960; 7: 198210.

28. Reyes G. Verrugas de cavidad oral. Rev Colegio Med (Guatemala). 1962; 13: 223-229.

29. Soneria A, Fonseca N. Sobre una lesión de la mucosa oral en los niños de la misión de Los Angeles de Tokuko. Venezuela Odont. 1964; 29: 109.

30. Syrjänen SMM. Human papillomavirus infection in the oral cavity in: Syrjänen K, Gissmann L, and Koss LG. (Eds). Patilomaviruses and Human Disease. Springer-Verlag. Ne York. 1987; 88: 104.

31. Grinspan D, Abulafia J. Papilomatosis florida bucal Med Cut ILA. 1985; 13: 43-64. 